\title{
An important variety of organic gemstones-Agarwood
}

\begin{abstract}
Arif Hussain Kaleri ${ }^{1,2}$, Xi-Qiang Song ${ }^{1,2 *}$, Hao Fu Dai ${ }^{1,2}$, Asif Ali Kaleri $^{3}$, Nizamani Mir Muhammad ${ }^{4}$, Anum Mehmood ${ }^{5}$, Ghulam Sajjad Kaleri $^{3}$ and Abdul Rasheed Kaleri ${ }^{6}$

1. Key Laboratory of Genetics and Germplasm Innovation of Tropical Special Forest Trees and Ornamental Plants (Hainan University), Ministry of Education, College of Forestry, Hainan University, Haikou, P. R.-China

2. Key Laboratory of Germplasm Resources of Tropical Special Ornamental Plants of Hainan Province, College of Forestry, Hainan University, Haikou, P. R.-China

3. Department of Agronomy Sindh Agriculture University Tando Jam, Hyderabad, Sindh, 70060-Pakistan

4. Department of Biochemistry and Molecular Biology, Hainan University, Haikou-China

5. Hainan Key laboratory for sustainable utilization of tropical Bioresources, Institute of Tropical Agriculture and

Forestry, Hainan University, Haikou 570228-China

6. South East University of Science and Technology Mianyang Sichuan-China

*Corresponding author's email: songstrong@hainanu.edu,cn

Citation

Arif Hussain Kaleri, Xi-Qiang Song, Hao Fu Dai, Asif Ali Kaleri, Nizamani Mir Muhammad, Anum Mehmood, Ghulam Sajjad Kaleri and Abdul Rasheed Kaleri. An important variety of organic gemstones - Agarwood. Pure and Applied Biology. Vol. 9, Issue 2, pp1424-1435. http://dx.doi.org/10.19045/bspab.2020.90148
\end{abstract}

Received: $26 / 11 / 2019$

Revised: $13 / 02 / 2020$

Accepted: $18 / 02 / 2020$

Online First: 05/03/2020

\section{Abstract}

Agarwood study is getting importance day today because of its advancement in chemical benefits as well as benefits in healthcare. This study elaborates and reviews the detailed structure of agarwood with its benefits in medicine as well as our life. The agarwood has a high density and can sink in water. The aromatic components contained in it can emit fragrance. Agarwood has a magnificent, rare and durable gemstone character. Like ordinary organic gemstones, it is a collection of organic, inorganic and trace elements formed by animal and plant life activities. Long related resin line texture. The agarwood has a fine particle size, compact structure, low hardness, rich color, and luster. It is important to understand the benefits from the Agarwood with its chemical composition in order to get benefits that are cost-effective as well as health benefits.

Keywords: Aesthetic characteristics; Agarwood; Classification; Organic gemstone

\section{Introduction}

Ancient Shenmu, also known as "dark wood" and "Oriental Shenmu", are charcoal, silicified wood, calcified wood, and alcohol wood, which are formed in the layer when the ancient trees on the ground fall into the river. Etc., after thousands of years of deep-buried grinding, these woods have changed the composition, structure and physical properties. Although they still maintain the structural forms of the ancient trees, they have formed a thousand years of noncorruption [1]. Since ancient times, the ancient Shenmue has been the first choice for the emperors to build palaces and make caskets. The dignitaries and literati are regarded as ancient hemispheres and works of ancient wood carvings things. Agarwood is also a kind of ancient wood, but agarwood is agglomerate of agarwood resin and wood. 
In the existing literature reports, agarwood is mostly used in medicine and rarely used agarwood for carving art. According to its origin and characteristics, agarwood is also an important variety of organic gemstones.

\section{The scientific definition of Agarwood} Material grade division of Agarwood products

Integrated predecessor data [2], and divided the grades of agarwood, and divided the Chinese agarwood products into four grades according to the proportion of texture and surface resin (commonly known as oil grid): first-class agarwood should No white wood, heavyweight, black oil color, oil content accounts for more than $80 \%$ of the whole block; second-class agarwood is slightly white wood, oily black or Tan, oil grid accounted for more than $60 \%$ of the whole block; third-class agarwood white wood is more, oil grid accounted for more than $40 \%$ of the whole block; fourth-class agarwood white wood proportion, the texture is loose and frivolous, oil grid accounted for more than $25 \%$ of the whole block.

\section{Agarwood standard}

The 1977 edition of the Pharmacopoeia of the People's Republic of China stipulates that the alcohol-soluble extract of agarwood should not be less than $15 \%$, and the 2005 edition should not be less than 10\% [3] the agarwood with a resin content exceeding $25 \%$ can be used for medicinal purposes. The quality of agarwood is determined by the amount of resin [4]: color is black, all resin, no white wood is the first grade; heavyweight, multiresin, no white wood is the second grade; Specific provisions.

\section{Definition of gem-quality Agarwood}

The agarwood that sinks into the water has a high oil content and a darker color, and its hardness is greater than that of ordinary wood. The density of agarwood white wood is about $0.4 \sim 0.6 \mathrm{~g} / \mathrm{c} \mathrm{m} 3$. At this time, the white wood can't sink to water. Once the resin content of agarwood exceeds $1 / 4$ of the whole agarwood, any form of agarwood (tablet, Blocks, powders) can sink in water. The author believes that the density of gemquality agarwood is at least above the density of semi-submersible agarwood. Agarwood sculptor and Anhui Province The non-legacy inheritor Zheng Yujin believes that: Shen Xiang has a hard texture and full of oil and is an ideal engraving material. For most agarwood, the darker the color, the denser the texture and the better the quality.

The gemological characteristics of Agarwood and the authenticity evaluation technology

Significance of Agarwood

1. According to Fan Jufen's submerged water test, the density of agarwood is $0.87 \sim 1.80 \mathrm{~g}$ / c m3 [4]. The agarwood with a density greater than that of water can sink in the water, so it is called Shenshui; the semisinking and semi-floating (density is about 0.98 ) is a stack of incense; the floater is yellow ripe.

2. The agarwood resin contains aromatic components, so it can disperse the fragrance and emit aroma after burning. Agarwood has a variety of odors due to the different effects of tree species, strains and other factors. The aroma of different origins and colors is also different.

3. Agarwood is a resin-line structure formed by a large amount of secreted resin flowing along a wooden pipe, which is an identification feature of naturally occurring agarwood.

4. The agarwood incense is slow, and there is a saying that "a hundred years of incense and a thousand years of Qi Nan".

5. Agarwood contains volatile oil, which is flammable. When it burns, it produces white smoke. It can be seen that the oil is boiling and the white smoke is on the top.

6. Agarwood's of different origins and burial environments have different colors, such as green, dark green, gold (yellowish), yellow, black, and the like. 
7. The composition of agarwood granules is fine and compact, and it is harder than ordinary loose wood. It is an excellent material for engraving.

8. The aroma of agarwood: The high content of agarwood resin in the fine agarwood is so high. The grain size structure and luster characteristics of agarwood determine its suitable facial expression for engraving and creating characters.

9. Agarwood has rich aesthetics, culture, religion and philosophical implications.

Modern research on the chemical constituents of Agarwood

Before the 1970s, it was believed that linalool was the main component of agarwood, and modern tests proved that [5-10], agarwood resin components not only have alcohols but also sesquiterpenes (volatile components), 2 (2. phenethyl) chromone, triterpenoids, aromatics, fatty acids and other ingredients[11-15].

The evaluation technique of aloes authenticity

As a result of the lack of natural resources, the price of agarwood continued to soar. The agarwood "processing" became a profiteering industry, the technology of counterfeiting was upgraded, and the products on the market were rampant. Players are hard to avoid being cheated, so it is important to taste the quality of agarwood. Because agarwood is a fragrant wood that can sink into the water, "sinking water" and "smelling incensed" are the primary identification content. [16, 17].

Five methods of identification: "sink, see, touch, smell, burn".

\section{Shen}

The most intuitive way for the people to judge is the submerged method. During the aroma of the agarwood, the resin content will gradually increase, and the density of the agarwood resin will be large. When the resin content of the agarwood exceeds 1/4, the agarwood will sink into the water, so it is possible to judge the amount of resin in the agarwood by using the submerged water. High and low.

\section{Look}

The agarwood tree is evenly distributed along the wooden conduit during the fragrant process, and the oily lines are clearly visible. The artificially compressed material causes the oily line to be blurred, broken or unevenly distributed, which is quite different from the natural agarwood texture.

\section{Touch}

Rub the surface of the agarwood material with your hand. The real agarwood looks oily, but it doesn't stick to the touch. Agarwood is a condensate of fat and wood. Its oil is higher than solid wood, and it is not as dry and hard as solid wood. Although the fine agarwood can sink, if the "Agarwood" material sinks like metal and stone, it may be a "sinking stone" that is artificially suppressed. Although it can sink in water, it is fake.

\section{Smell}

The naturally occurring agarwood smell is mellow and sweet, and the fragrance is fragrant. Pay attention to the appreciation process. No fragrance is definitely not a real thing, but when the fragrance is unnatural or uncomfortable, pay attention to whether it is false.

\section{Burning}

Generally, the natural agarwood fragrance is light and elegant. It is difficult for beginners to distinguish. Sometimes it needs to be burned with fire or smoked with the electric incense burner. Experienced old players can come from the bursting of agarwood burning or the shape and color of smoke. Identify the authenticity. No matter under what circumstances, the aroma of agarwood will not be pungent. If there is a pungent smell of black smoke, it must be a fake. [18-20] 
Formation conditions and classification of Agarwood

\section{Natural conditions of Agarwood}

The main growing areas of agarwood in China are Guangdong, Guangxi, Hainan, and Taiwan. In foreign countries, they mainly grow in Southeast Asia such as Vietnam, Malaysia, Indonesia, and the Philippines. Due to over-harvesting in recent years, wild agarwood resources are already scarce. Agarwood has been included in the international protection of trees forbidden from felling and exporting. Aquilaria Sinensis has high requirements on the climate, soil, temperature and humidity of the growing environment. It is suitable for growing in warm and humid Southeast Asia and it is difficult to be transplanted to other places to survive. At the same time, the trees are loose and easy to break, hurt or even die. Therefore, it is also difficult to adapt to the natural environment where sand is large. When the temperature is lower than $-2{ }^{\circ} \mathrm{C}$, it is difficult to survive. A scented tree has to bear a higher quality Agarwood, in addition to having a suitable living environment, must have a mature and well-developed resin line, which usually requires more than 10 years of tree formation. Because the trees are harsh on the environment, wild agarwood trees have a lifespan of at least one or two hundred years.

\section{Classification of agarwood}

According to the reasons for the formation of agarwood, it is mainly divided into the following categories.

(1) an environment where sand is large. When the temperature is lower than $-2{ }^{\circ} \mathrm{C}$, it is difficult to survive. A scented tree has to bear a higher quality Agarwood, in addition to having a suitable living environment, must have a mature and well-developed resin line, which usually requires more than 10 years of tree formation. Because the trees are harsh on the environment, wild agarwood trees have a lifespan of at least one or two hundred years.
(2) Classification of agarwood According to the reasons for the formation of agarwood, it is mainly divided into the following categories. Agarwood. The knot, the agarwood excavated from the still-growing agarwood, is fatted by injury, bacterial erosion or natural lesions. During the growth of trees, agarwood trees urge the resin to protect itself from lying close to the wound after being subjected to external forces such as axe felling, insect repellents and insects that cause deep wounds.

(3) Agarwood is the agarwood that is extracted from the soil. The agarwood tree was hidden underground for natural reasons. After a few hundred years or even thousands of years of gestation, it was called agarwood. (4) Water agarwood, also known as water grain agarwood, water agarwood. Mainly refers to the agarwood formed after the body is separated from the fragrant wood and enters the moist mud and marsh. The water agarwood is generally black in color and protected by moisture. The weathering of the body is not serious. Therefore, even if it is cooked, its grease lines are still clearly visible, and the water is firm and tough, and the body is generally thick.

(5) Qi Nanxiang. In addition to the above four kinds, there is also a special type of variety, often self-contained, known as Qi Nanxiang, also known as Che Nanxiang, Galois, which is the aristocrat in the agarwood. The cause of Qi Nanxiang is slightly different from that of ordinary agarwood. Therefore, there are many differences in the morphology of the two. Generally, the agarwood has a high hardness and a small smell. In the case of fire, the fragrance can be emitted. The fragrant process is mixed with natural stone, honey. The hardness is softened by the incorporation of stone honey, but its aroma is sweet and large due to the stone honey. It can also emit a strong sweet smell without burning fire. It is called the "king of the incense". "The best in the fragrance". Fig. 1 shows the detail 
comparison of different countries which are producing agarwood and importing also.

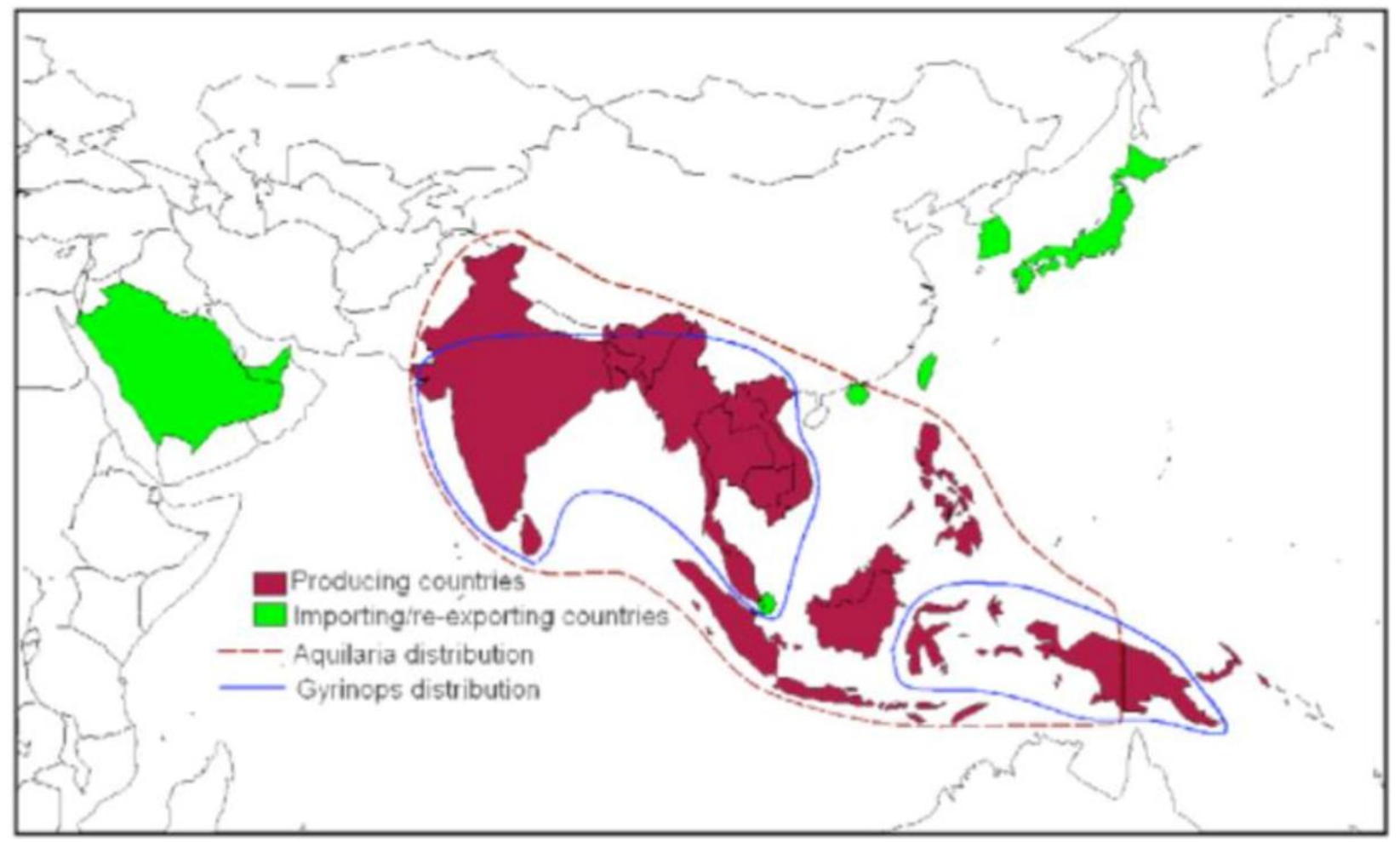

Figure 1. Agarwood Producing and importing countries

The hardness, smell and oil line of Qi Nan Xiang is different: Qi Nan is not as dense as ordinary agar and fine agarwood. Ordinary agarwood is hard, Qi Nan is soft and sticky, cut and even fragrant. However, it is almost oily after cutting. Under the microscope, the grease lines in the common agarwood are concentrated together, while the oil line of Qi Nan is vivid. Identification of Qi Nan, mainly in its fragrance: First, Qi Nan has a cool and sweet taste under normal conditions; Second, the fragrance that Qi Nan radiates after being heated is not only like a silky blue smoke, but also Three-stage change, with the first fragrance, the fragrance and the tail fragrance. For example, after the burning of the first fragrance (the first fragrance) is light and elegant, and then turned into a sweet and cool fragrance, and the tail fragrance has almond flavor [21]. According [20], the difference between Qi nan and common agarwood is that: (1) the oil content in Qi nan is significantly higher than that of ordinary agarwood; (2) Compound 2 (2-phenethyl) in Qi nan The relative content of ketone and [22]. (4-methoxyphenyl) ethyl] chrome is as high as $37.30 \% \sim 84.71 \%$, and only $0.16 \% \sim$ 13.30 in common agarwood. $\%$, and these two compounds contribute greatly to the change in the aroma of agarwood when heated.

\section{The aesthetic implications of Agarwood}

Agarwood is the only resin gem that can sink in the water and disperse the fragrance. It is a scarce resource collection, a carrier of traditional Chinese culture, good medicine for calming yin and yang; a famous product for making tea, bartending, and hospitality, or the fragrance of the perfume is modulated; its aesthetics is rich, and it is the carrier of 
carving and artistic creation. Shen Xiangmei is in material, more beautiful in spirit.

\section{texture aesthetic implications}

The beauty of agarwood is in Chen, knot, greasy, real, disabling, and dry. Chen: Good fragrance will age, like wine, the more fragrant, the accumulation of years; knot: the process of aroma, first inlaid along the texture of the tree, gradually feel like a floating smoke, after Gradually like thick clouds and thick fog, until it becomes a piece of crystal; greasy: it is a sense of grease, the surface will have grease luster, the viscosity and toughness of good fragrance are extremely strong; real: tight and not loose, can sink; water: residual Its watch, weatherbeaten agarwood is extraordinary, irregular shape is like the thin stone and dead wood in Chinese painting, it has a different kind of beauty; dry: it is the Buddha's feelings, everything is dry and endless, this is the natural power of the law. Rooted in the ground, the branches are rooted in the roots, and the leaves are attached to the branches; but whenever the things are derived, they are all reincarnation, and they always come and go. Although they are reminded by the wind and rain, they also look at the green and green things. Phase, magical magical season, selfsufficiency, it is painless and painless,

\section{The beauty of the Agarwood spirit}

The smell and spirit are related to each other. The agarwood has no odor, clear and pure, long, and people can't help but capture the rare purity in the smell of the earth. Close your eyes and condense the heart, and the heart will be touched and calm. Scented and quiet, quiet and affectionate, the literati always let the material serve the spirit.

People who love incense have common characteristics, that is, temperament is calm and open-minded, and they have a deep understanding of life. They can understand the mystery of life. The beauty of agarwood is in China, and the art of agarwood is in
China. Let this civilization come into the long river of history. Keep moving forward.

Agarwood is like a good teacher and a friend. With the fragrance, the people who love the incense are connected together. Agarwood is the medium of thought for interpersonal communication. The fragrance is not only a habit, but also a state of mind, a state of mind that is not anxious, calm, and calm; you will find that communication becomes smoother and your thinking is more active, Scent to isolate the world's impetuous, to return to the truth. Take Aquilaria as a medium, meet friends, talk about ambition, talk about life, and exchange insights. It's so simple to smell people and know people [5].

\section{Agarwood important}

The elegance of agarwood is not only because of its mellow taste and high quality but also because of the moral concept contained in the formation mechanism of agarwood. The calligrapher of the Song Dynasty, Huang Tingjian, recorded the "Xiang Shied": "Ghosts and spirits, clear mind and body, decontamination, sleep, Jingzhong Cheng you, sneak in the dust, more than not tired, widowed, long-lasting immortal, commonly used without obstacles. Combining the ancient and modern agarwood culture, the excerpts of the agaric moral implication are as follows:

1. Agarwood is fragrant and fragrant. The agarwood tree is called white wood before it is fragrant, and its density is only $0.4 \sim 0.6 \mathrm{~g} /$ $\mathrm{c} \mathrm{m} 3$. It will not sink into the bottom without fragrance. When the old agarwood is injured, the tree is festered around the wound due to bacterial infection. In order to prevent the agarwood tree from continuing to fester, the agarwood tree secretes the sap to make the tree immune system play a role so that the agarwood resin and the woody ingredients form a condensate. This fragrant process is like a phoenix nibble so that the general white wood gets a new life. With the increase of linalool, it becomes high-grade agarwood, 
completes the process of aroma, and makes agarwood a sacred object that can communicate with God. The agarwood tree secretes a large amount of resin due to injury, making it good medicine for curing all diseases, reflecting the spirit of "killing and saving people".

2. Agarwood is a gentleman who "reports with morality". Agarwood is fragrant due to injury and forms in the pain. However, after the agarwood is formed, the insect ants and bacteria that harm the mother are not harmed. In destruction, implied that the road is merciful. For the purpose of probation, education, not elimination and destruction. The formation of agarwood is natural, so it is believed that agarwood does have a gas field, and this kind of annihilation is where the agarwood is.

3. Agarwood's immunity: Agarwood attracts insects, but agarwood can deworm. The painful tree is very perishable, but the painful tree is not corrupted and immortal. A piece of agarwood, no matter how high the content of agarwood resin, always contains wood, there are many agarwood and mud on the mountain. If the resin itself does not deteriorate, the insect does not eat wild animals, the product is made of agarwood and wood. His immunity is enhanced and becomes a new magical sacred object.

4. "Unpretentious and low-key man" is never publicized, "Deadwood" can be carved! The appearance of agarwood seems to be a kind of deadwood, but it is essentially different from the general deadwood. It is a condensate of linalool and white wood. It can sink into the bottom of the water and can emit aroma. Its value is very high. The price of diamonds is many times that of gold. It's simple and rough appearance masks the excellent qualities of its value. Agarwood is harder than white wood and is the best material for artistic carving.

5. Admire the ancestors and communicate with the ghosts. The aroma of agarwood is elegant and elegant, and the smoke is white and straight into the sky, making Aquilaria a sacred object that can communicate with God in many religions. China's fragrant culture has a long history. To worship the ancestors, we need to burn incense and burn the paper. The aroma of agarwood is not only the characteristics of ordinary fragrance but also the fragrance, which is more connotation of respecting the gods.

6. Relieve and refresh yourself. The aroma of agarwood requires a calming down of the heart so that the fragrance has a remarkable calming effect. In addition, the elegant aroma of agarwood is very calming, and people who are familiar with the taste smell this kind of smell, and there is a feeling of peace, which can even make people sleep. In the process of scenting, people can eliminate the impetuous mood, and it is easier to achieve the realm of "clean heart". The gentleness and elegance of the agarwood give peace of mind. When you taste the agarwood, you need to be fragrant and calm, so that you can deeply feel the wonderful world of agarwood fragrance.

7. It is good for feelings and enlightenment. Since ancient times, the ancients believed that the good aroma is not only fragrant and pleasant, but also can lead to cleansing, reconciling the body and mind, and cultivating sentiment. Confucianism has always been said to be fragrant. "Xunzi-Bao Li," said: "Indica rice beam, five flavors of fragrance, so raise the mouth also; pepper Lanfen, so nourish the nose; ... the gift of the raise also." The fragrance activity is not simply a smell. When some people with rich ideas and rich feelings gather together for a fragrance, the fragrance friends not only achieve sensory pleasure, but also mutual There will be a collision of thoughts, a kind of exchange of insights, a fusion of thoughts, and the so-called scent of the scent.

8. Health care, rumors, and rumors. The activity of scent is mainly achieved through the sense of smell. The human olfactory 
system (the olfactory nervous system and the nasal trigeminal nervous system) senses the odor molecules in the air and then transmits nerve stimuli to the brain through nerve cells to make the human body perceive. Chinese medicine believes that odor can enter various parts of the body through the body's meridians, thus affecting the body's role in the system. Therefore, a good aroma has the functions of regulating blood circulation, passing through meridians, and discharging toxins; relatively speaking, bad gas will damage the internal balance of the human body and cause damage to human health.

9. The bacteria cause rot and the fragrant scent can cause cleanliness and beautify the environment. The agarwood tree rots due to bacteria, and its defense system secretes resin to prevent corrosion and completes the aroma process so that the agarwood has the functions of sterilization, insect prevention, beautifying the environment and protecting the ecology.

10. The scent of the scent, the chest and the mind, exchanges into friends. Choosing likeminded "sweet friends", the experienced "fragrance master" achieves "purifying the soul, appraising the beauty, inspiring the Hanwen, reconciling the body and mind" through the "fragrance seat" activity, focusing on the inner spiritual influence and benefiting the spiritual world. Through the fragrance, you can relax and remove your troubles.

\section{Discussion}

In the history of our country, Agarwood is a favorite collection of the upper class, such as the royal family, the nobles, the rich, the writers and the writers. The ordinary people can't touch it. However, with the deepening of reforms, people's living standards are constantly improving, and more and more people are paying attention to it. A material that can sink and scent. For a time, the Expo opened the Expo and established the Agarwood Association. The auction houses continued to introduce finished products related to agarwood. Even some stalls began to do the business of agarwood. The price of agarwood was also fired in the past two or three years. More than ten times. With the development of society, people's living standards have been further improved. People's attention has shifted from food and clothing to investment and financial management. They are constantly looking for profitable investments and looking for products with good appreciation. 20 years ago, people put their investment points on the stone, and the price of jade and jade has increased by a hundred times. Many people have felt that there is no room for appreciation, and many resources have been exhausted. At this time, many people put their attention on the "wood". First, Huanghuali, red sandalwood and golden nan, a few years ago, began to pay attention to the collection of agarwood in recent years. Agarwood is known as the "wooden house", and from its rarity, it is almost nonrenewable; from an artistic point of view, agarwood crafts cannot be copied. From the aspects of medicinal efficacy, ecological function, health and so on, the collection of agarwood The value is even better.

In the early 1990s, many people still did not realize the value of agarwood. At that time, the price of agarwood was basically several hundred yuan and one kilogram. In 200 years, it basically reached several thousand yuan $/ \mathrm{kg}$. In the first half of 2001, the submerged The average price of agarwood is several hundred thousand yuan $/ \mathrm{kg}$, and the old material of the submersible level will be more expensive. From the collection of more, as long as the submersible level of materials, bracelets or carvings can be included in the bag, of course, but also according to their own economic strength; collection of old objects of the Ming and Qing Dynasties, or contemporary well-known engraving masters The work is also a good choice. Since it takes 
more than a century to make this agarwood material, and the material is scarce, there is only a large amount of it. Since Aquileia is also regarded as one of the key protected species in the 1973 International Convention for the Protection of Wildlife, Shannon's are not free to adopt wild agarwood. Much wild agarwood's in the market are harvested by Shannon in the past few decades as shown in (Fig. 2). In recent years, the agarwood with

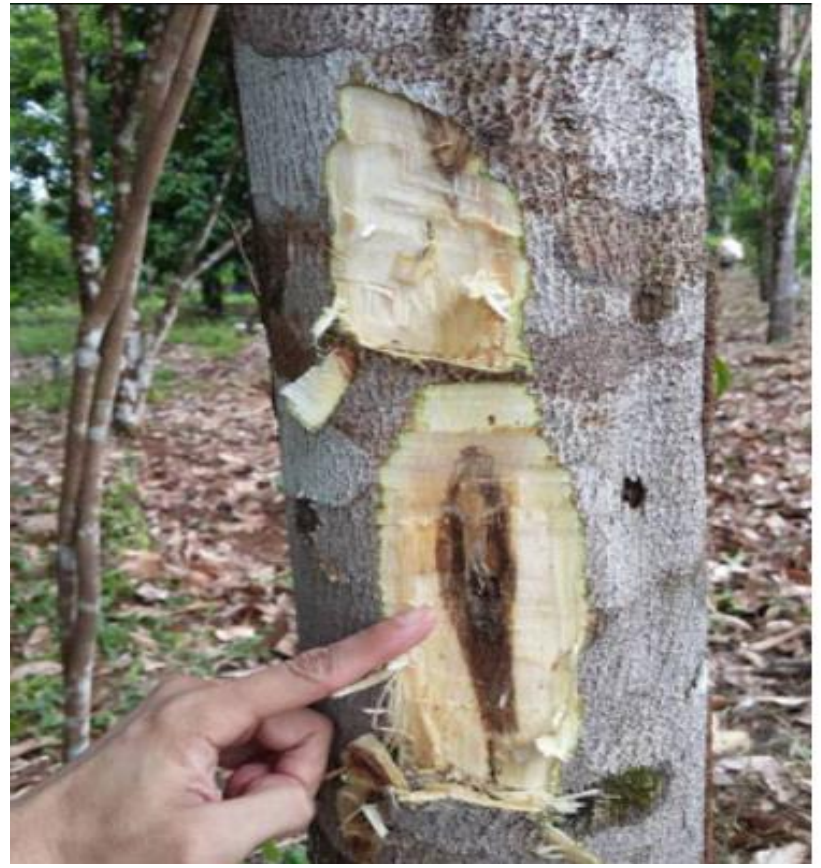

Figure 2. Harvesting techniques of Agarwood

Agarwood has the gemstone's magnificent, rare and durable basic conditions

(1) Magnificent: Generally speaking, the color is beautiful, pure and gorgeous, and the light is good. In addition to a variety of colors and grease luster, Agarwood also emits aroma, which is not found in general gemstones, so the color of agarwood is more abundant than ordinary gemstones.

(2) Rare: Because of the harsh living conditions of agarwood, the aroma is very slow, cannot be copied, cannot be regenerated, and is widely developed. Therefore, the market is more out of stock, and it is rarer than ordinary gemstones. artificial planting and artificial incense has been mostly. At present, there have been a lot of acquisitions of agarwood in the background of the group, which has led to a sharp rise in the price of the agarwood market in the past five or six years. If you really want to find a string of sinkers in a good place in the market, it is not very easy. There are many opportunities to come across.

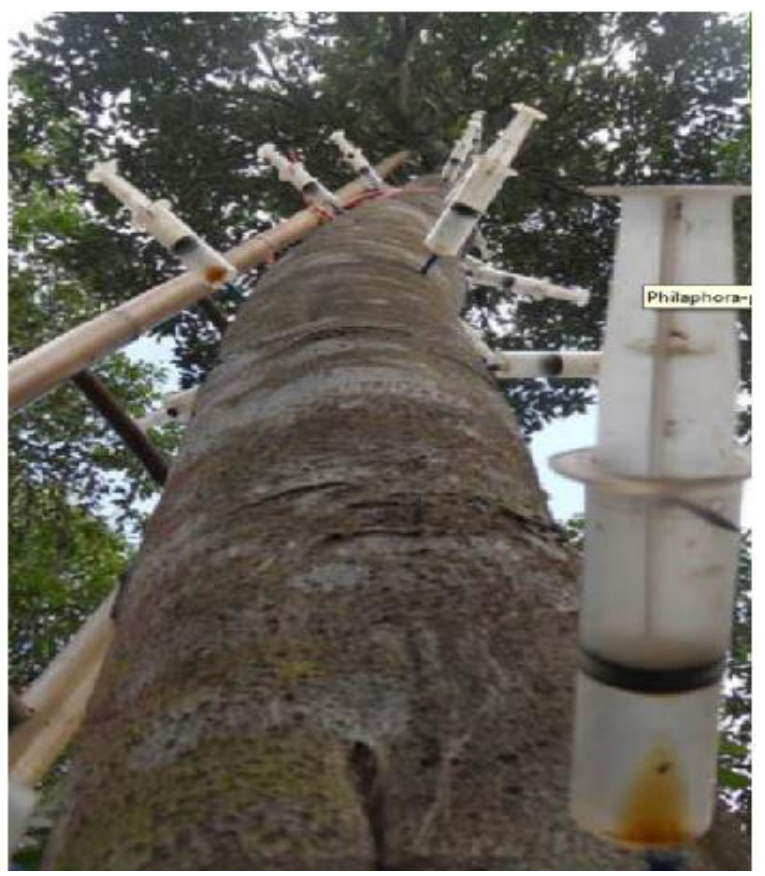

(3) Durability: Like other organic gemstones, the hardness of agarwood is small, with a texture of life and texture, a certain degree of toughness, or a material that is not bad for thousands of years. Agarwood is a combination of resin and white wood. After the aroma, it completely changes the original properties of white wood. It has become a special crystalline substance. Therefore, it is entirely reasonable to classify agarwood as an organic gem.

Agarwood is an important variety of organic gemstones:

The first part of China's published "Optical Stone Science" 
[23]: “Organic gemstones are organic minerals that meet the requirements of gemstone craftsmanship by the ancient metabolism of paleontology or modern organisms. Organic gemstone material. "Agarwood is a material formed by a resin secreted by modern plant agarwood that sinks into the water and releases a fragrance. Therefore, agarwood belongs to a variety of organic gemstones. The reasons are shown below:

(1) Organic gemstones are a collection of organic, inorganic and trace elements. Agarwood is coagulation of wood and resin. Agarwood is rich in mineral elements such as Calcium (Ca), Magnesium ( $\mathrm{Mg}$ ), Magnate $(\mathrm{Mn})$, Felium $(\mathrm{Fe})$, Zinc ( $\mathrm{Zn})$ and Curium (Cu) [24].

(2) The formation of organic gemstones is closely related to life activities and forms texture patterns related to biological growth, such as concentric circles and spiral patterns on the cross-section of the pearl, the zither pattern of the ivory, and the annual ring pattern of the silicified wood. The aroma of the agarwood is the resin line formed by the resin flowing along the wooden pipe.

(3) Agarwood has a resin content (international standard) of more than $25 \%$, which makes the agarwood denser than the loose white wood, and the resin density is high so that the agarwood can sink in the water.

(4) The aromatic component of the resin of agarwood determines its ability to emit fragrance. The volatile components in the resin can emit white smoke and burn directly. Therefore, Aquilaria is regarded by religious believers as a sacred item that can communicate with the Upper Canyon.

(5) The pearl is made of mother-of-pearl, and the agarwood is agarwood. The former is caused by the life process of the animal, and the agarwood is caused by the metabolism and alienation of the plant. In addition, agarwood can cause natural disasters, animals, bacteria and human activities. Therefore, it can be said that agarwood is formed by the joint action of animals and plants.

(6) Amber is formed by the resin of pines falling into the ground and jade formed by the resin lining of the agarwood tree buried in the ground or in the ground, in wetlands, swamps, etc.. Whether it is amber or agarwood, resin plays a leading role. Why can amber be classified as an organic gemstone, and agarwood cannot be classified as an organic gem.

(7) Organic gemstones are mostly opaque or translucent except for amber, and agarwood also opaque.

(8) Organic gemstones are rich in color and varied. Agarwood is produced in a variety of colors under different conditions.

(9) Compared with inorganic gemstones, organic gemstones are not high in hardness. Except that Qi Nan is soft and sticky, the hardness of ordinary agarwood is higher than that of white wood.

(10) The organic gemstone has fine grain size and compact structure, and the resin has more oil fat, such as ebony in the ancient wood, black and black oil; and the ancient wood structure such as agarwood is dense, and the grease is lustrous, which is also suitable for Engraving creation.

(11) Organic gemstones have complex processes related to liver metabolism, and their color and shape change greatly, so the cultural morality of anthropomorphic is rich. This article can be summarized in the avantgarde virtues such as "reporting grievances with morality", "can be carved by wood" and "unpretentiousness".

(12) Agarwood, like many kinds of organic gemstones, is "the gold in medicine" and is the first of its kind in South China. It has a scent of scent, bitterness, and mild warmth. It has the effects of relieving pain, warming and helping the resistance, calming the breath, reducing the air and removing the dryness, 
warming the stomach and nourishing the spleen, and venting the stomach and vomiting. Since ancient times, the folks in our country have said that "there is a box of jewels, not as good as the ebony side". This is because the formation of ancient sapwood is a process of jade. The best ancient sapwood can be compared with jade, which can be called "woody jade." ". Also, due to the everchanging conditions of ancient saplings, the quality of the sapphire is strong and the quaintness of the wood and the charm of the stone. The ancient sapwood has unique innate conditions for the creation of sculpture art. Therefore, from the perspective of artistic creation, the ancient sapwood Engraving art is more original, which is unmatched by ordinary gemstones. In addition, because China is an ancient jade country, it is classified as jadeite jade, produced in Myanmar, with a green and red dragonfly as beauty; and Hattian jade is produced in Xinjiang, with white jade as the most beautiful, which is two different aesthetic concepts.

\section{Conclusion}

The agarwood is delicate, compact and warm in color, with classic and elegant beauty. At present, the jewelry industry has classified silicified wood in ancient woods as organic gemstones. Calcified wood in ancient wood is slightly soluble in water and loose in texture. It is difficult to classify as a gemstone, but agarwood and ebony have a series of excellent gemological characteristics, which can be considered as organic gemstones. In summary, whether it is from the mechanism of, material composition, geological characteristics, structural and structural characteristics, or the medicinal value and cultural implication of agarwood, we all have reason to say that agarwood is an organic gemstone. An important variety, called "plant diamonds", is a gemstone material that can be compared to gold.

\section{Authors' contributions}

Conceived and designed the experiments: AA Kaleri, NM Muhammad, XQ Song \& HF Dai, Performed the experiments: AH Kaleri, XQ Song \& HF Dai, Analyzed the data: AH Kaleri, XQ Song, HF Dai, A Mehmood, NM Muhammad, Contributed materials/ analysis/ tools: A Mehmood, GS Kaleri \& AR Kaleri, Wrote the paper: XQ Song, HF Dai, A Mehmood \& NM Muhammad.

\section{Acknowledgments}

This research was financially supported by the Innovative Research Team Program of Hainan Natural Science Fund, Grant/Award Number: 2018CXTD331 and the High Level Talent Project of Basic and Applied Basic Research Plan (Natural Science Field) of Hainan Province in 2019 (2019RC135).

\section{References}

1. Tan CS, Isa NM, \& Zainal Z (2019). Agarwood induction: current developments and future perspectives. Front Plant Sci 10: 122.

2. Nugroho WD, Pujiarti R \& Tiyasa NP (2019). Wood anatomical characteristics of agarwood-producing species (Aquilaria sp.). Wood Res 64(5): 759-768.

3. Chhipa H, Chowdhary K \& Kaushik N (2017). Artificial production of agarwood oil in Aquilaria sp. by fungi: a review. Phytochem Rev 16(5): 835-860.

4. Liu YY, Wei JH, Gao ZH, Zhang Z \& Lyu JC (2017). A review of quality assessment and grading for agarwood. Chin Herb Med 9(1): 22-30.

5. Hoque M, Mondal M, \& Khan M (2019). Insect infested agarwood: A newly prized product of agarwood market in Bangladesh. Fundam Appl Agric.

6. Mishra G (2018). Heartwood formation and the chemical basis of natural durability in Eucalyptus bosistoana.

7. Yang Y \& Chen Y (1986). Study on the chemical constituents of domestic agarwood II. Separation and structure of white wood alcohol and dehydrogenated white wood alcohol. J Pharm Sci 21 (7): 516-520. 
8. Huang M, Han H, Wang H, Li L, Zhang Y \& Bhatti U A (2018). A clinical decision support framework for heterogeneous data sources. IEEE J Biomed Health 22(6): 1824-1833.

9. Chen HQ, Wei JH, Yang JS, Zhang Z, Yang Y, Gao ZH ... \& Gong B (2012). Chemical constituents of agarwood originating from the endemic genus Aquilaria plants. Chem Biodivers 9(2): 236-250.

10. Nizamani MM, Nizamani FG, Rind RA, Khokhar AA, Mehmood A \& Nizamani M (2020). Heritability and genetic variability estimates in $\mathrm{F} 3$ populations of bread wheat (Triticum aestivum L.). Pure Appl Boil 9(1): 352-368

11. Wang MR, Li W, Luo S, Zhao X, Ma CH \& Liu SX (2018). GC-MS Study of the Chemical Components of Different Aquilaria sinensis (Lour.) Gilgorgans and Agarwood from Different Asian Countries. Mol 23(9): 2168.

12. Azren PD, Lee SY, Emang D \& Mohamed R (2019). History and perspectives of induction technology for agarwood production from cultivated Aquilaria in Asia: a review. J for Res 30(1): 1-11.

13. Bhatti U A, Huang $M$, Wu D, Zhang Y, Mehmood A \& Han H (2019). Recommendation system using feature extraction and pattern recognition in clinical care systems. Enterp Inf Syst-Uk 13(3): 329-351.

14. Halcomb JS (2019). Trees with a heart of gold-identifying first steps to the preservation of Agarwood and Sandalwood. Master Thesis Series in Environ Studies and Sustainability Sci.

15. Nizamani MM, Nizamani FG, Rind RA \& Khokhar AA (2019). Assessment of genetic variability and heritability estimates in $\mathrm{F} 2$ populations of bread wheat (Triticum aestivum L.). Discov Agri 5: 177-188.
16. Yin $Y$, Jiao L, Dong M, Jiang X \& Zhang $S$ (2016). Wood resources, identification, and utilization of agarwood in China. Springer 21-38.

17. Wenli M, Zeng Y \& Liu J (2007). GC-MS analysis of five batches of domestic agarwood volatile components. Chin Herb Med 30(5): 551-555.

18. Shu-Yuan QI (1995). Aquilaria species: In vitro culture and the production eaglewood (agarwood). In Medicinal and Aromatic Plants VIII. Springer pp 36-46.

19. Borges RM (2015). Fruit and seed volatiles: multiple stage settings, actors and props in an evolutionary play. J Indian I Sci 95(1): 93-104.

20. Yang D, Wenli N \& Yang J (2014). GCMS analysis of four kinds of sesquiterpene and 2-(2-phenylethyl) chromones in four kinds of scented scent. J Trop Crop 35(6): 1235-1243.

21. Balick M (2014). Rodale's 21st-century Herbal: A Practical Guide for Healthy Living Using Nature's Most Powerful Plants. Rodale Books. Balick, M. (2014). Rodale's 21st-century Herbal: A Practical Guide for Healthy Living Using Nature's Most Powerful Plants. Rodale Books.

22. Jung D (2013). The Cultural Biography of Agarwood-perfumery in eastern Asia and the Asian neighbourhood. J Res Asiat Soc 23(1): 103-125.

23. Khokhar AA, Jatoi WA, Nizamani FG, Rind RA, Nizamani MM, Wang HF, Mehmood A \& Khokhar MU (2019). Study of heterosis analysis in F1 population of bread wheat. Pure Appl Biol 8(2): 1757-1770.

24. Hu G, Huang W \& Cheng WZ (2010). Comparison of distribution characteristics of six mineral elements in agarwood and decoction from two habitats. Chem Analysis 19(1): 23-26. 